\title{
Independent associations of socioeconomic factors with disability and pain in adults with knee osteoarthritis
}

Rebecca J Cleveland', My-Linh N Luong ${ }^{2}$, Joshua B Knight ${ }^{3}$, Britta Schoster ${ }^{1}$, Jordan B Renner ${ }^{4}$, Joanne M Jordan ${ }^{5}$ and Leigh F Callahan ${ }^{*}$

\begin{abstract}
Background: The purpose of this study is to explore the relationship between function, pain and stiffness outcomes with individual and community socioeconomic status (SES) measures among individuals with radiographic knee osteoarthritis (rOA).
\end{abstract}

Methods: Cross-sectional data from the Johnston County Osteoarthritis Project were analyzed for adults age 45 and older with knee rOA $(n=782)$ and a subset with both radiographic and symptomatic knee OA $(n=471)$. Function, pain and stiffness were measured using the Western Ontario and McMasters Universities Index of Osteoarthritis (WOMAC). Individual SES measures included educational attainment ( $<12$ years, $\geq 12$ years) and occupation type (managerial, non-managerial), while community SES was measured using Census block group poverty rate $(<12 \%, 12-25 \%, \geq 25 \%)$. SES measures were individually and simultaneously examined in linear regression models adjusting for age, gender, race, body mass index (BMI), occupational physical activity score (PAS), comorbidity count, and presence of hip symptoms.

Results: In analyses among all individuals with $\mathrm{rOA}$, models which included individual SES measures were observed to show that occupation was significantly associated with WOMAC Function ( $\beta=2.91$, 95\% Confidence Interval $(C l)=0.68-5.14)$, WOMAC Pain ( $\beta=0.93,95 \% \mathrm{Cl}=0.26-1.59)$ and WOMAC Total scores $(\beta=4.05,95 \% \mathrm{Cl}=1.04-7.05)$, and education was significantly associated with WOMAC Function ( $\beta=3.57,95 \% \mathrm{Cl}=1.25-5.90)$ and WOMAC Total ( $\beta=4.56,95 \% \mathrm{Cl}=1.41-7.70$ ) scores. In multivariable models including all SES measures simultaneously, most associations were attenuated. However, statistically significant results for education remained between WOMAC Function ( $\beta=2.83,95 \% \mathrm{Cl}=0.38-5.28)$ and WOMAC Total $(\beta=3.48,95 \% \mathrm{Cl}=0.18-6.78$ ), as well as for the association between occupation and WOMAC Pain ( $\beta=0.78,95 \% \mathrm{Cl}=0.08-1.48)$. In $\mathrm{rOA}$ subgroup analyses restricted to those with symptoms, we observed a significant increase in WOMAC Pain $(\beta=1.36,95 \% \mathrm{Cl}=0.07-2.66)$ among individuals living in a block group with poverty rates greater than $25 \%$, an association that remained when all SES measures were considered simultaneously ( $\beta=1.35,95 \% \mathrm{Cl}=0.06-2.64$ ).

Conclusions: Lower individual and community SES are both associated with worse function and pain among adults with knee rOA.

Keywords: Osteoarthritis, Knee, Pain evaluation, Education, Occupation, Poverty, Social class, Socioeconomic

\footnotetext{
* Correspondence: leigh_callahan@med.unc.edu

${ }^{6}$ Thurston Arthritis Research Center and Departments of Medicine and Social Medicine, University of North Carolina at Chapel Hill, Chapel Hill, NC, USA Full list of author information is available at the end of the article
} 


\section{Background}

Arthritis, and particularly osteoarthritis (OA), is a common chronic disease in the U.S. [1-3] that is a frequent source of chronic pain and a leading cause of disability among older adults [4-6]. The prevalence of OA is expected to increase in the coming decades [7-9], with substantial cost implications for the health care system [10-12]. The knee is the most common joint associated with disability in OA; nearly 600, 000 persons with knee OA opt for total knee replacement every year in the U.S. [13], and the total number of knee replacements is expected to grow to 3.48 million by 2030 [14].

Research has identified individual-level risk factors for $\mathrm{OA}$, such as advancing age and female gender [1]. An individual's socioeconomic status (SES) may also increase the risk for $\mathrm{OA}$ and associated disability. The earliest study exploring the potential role of SES in OA was conducted by Hannan and colleagues [15], which found low educational attainment to be associated with reporting more knee pain and arthritis at any joint. Research has also shown that workplace conditions and occupations requiring strenuous physical movement, such as kneeling or heavy lifting, are associated with increased risk for knee and/or hip OA [16-19]. Johnston County Osteoarthritis (JoCo OA) Project studies have further supported the association of educational attainment and occupation with the prevalence of knee and hip OA in a community sample of Caucasian and African American adults age 45 and beyond [20-22]. Further, individual SES characteristics have also been associated with selfreported pain, physical function and disability among adults with knee and/or hip OA, including educational level $[23,24]$, occupation type [24], employment/retirement status [25], and social class [25].

In addition to individual SES characteristics, community SES factors may also contribute to the risk of developing $\mathrm{OA}$ and associated pain and physical function. Research from the JoCo OA Project has shown that both low levels of educational attainment and living in a community with a household poverty rate greater than $25 \%$ are independently associated with the risk for radiographic and symptomatic knee OA, even after adjusting for occupation and primary risk factors for knee OA [20]. Similarly, educational attainment and community poverty are associated with the risk for radiographic and symptomatic hip OA [22]. Low education, non-managerial occupation and high poverty rate are associated with less function, and more pain and stiffness in individuals with radiographic and symptomatic hip OA [24].

There have been no known studies to date which have investigated the association between SES factors and functional impairment (or disability), pain and stiffness among those with radiographically defined knee OA. Identification of SES factors that may predict disability among individuals with knee OA could aid clinicians in management of a patient's OA. The purpose of this investigation is to explore the relationship between physical function, pain and stiffness outcomes with individual SES (education and occupation) and community SES (block group poverty rate) among Caucasian and African American adults with radiographic knee OA (rOA).

\section{Methods}

The cross-sectional sample investigated in this study was composed of baseline participants in the JoCo OA Project who returned for follow-up in 1999-2004 ( $\mathrm{n}=$ $1935)$ or were newly recruited in 2003-2004 ( $\mathrm{n}=1150)$. The JoCo OA Project is an ongoing, longitudinal, population-based study of knee and hip OA that includes both rural and urban communities in Johnston County, North Carolina. The design of the JoCo OA Project has been described in detail in a previous publication [26]. A total of 3,085 participants were available for analysis, of which 2,385 had completed all household interviews and clinic visits. Our sample consists of individuals with radiologically confirmed knee $\mathrm{OA}$ and a complete WOMAC data $(\mathrm{n}=900)$ (Figure 1). Study parameters were approved by the Institutional Review Boards of both the Centers for Disease Control and Prevention (CDC) and the School of Medicine at the University of North Carolina at Chapel Hill. All participants gave written informed consent at the time of recruitment.

\section{Radiographic osteoarthritis assessment}

In clinical exams, posterior-anterior radiographs of the knee were obtained and interpreted by a radiologist (JBR) who scored OA on the Kellgren-Lawrence (K-L) scale from 0 to 4 [27]. Presence of rOA was defined as $\mathrm{K}-\mathrm{L}$ grade at 2 or higher. Both inter-rater reliability and intra-rater reliability were high (weighted inter-rater reliability $=0.86$; кappa for intra-rater reliability $=0.89)$ [28]. A total of 782 participants with complete outcomes, covariates and SES variables had knee rOA (Figure 1).

\section{Symptomatic knee osteoarthritis assessment}

Individuals with $\mathrm{rOA}$ and who had an affirmative response ("Yes") to the question "On most days, do you have pain, aching or stiffness in your [left/right] knee?" were classified as experiencing symptomatic knee OA. Participants with symptomatic knee OA are a subset of those with $\mathrm{rOA}(\mathrm{n}=471$, Figure 1$)$ who also have pain in the same knee.

\section{Outcome measures: function, pain and stiffness}

The Western Ontario and McMaster Universities Index of Osteoarthritis (WOMAC) questionnaire was used to assess physical functioning, pain and stiffness in hip and knee OA [29,30]. Responses to the WOMAC 


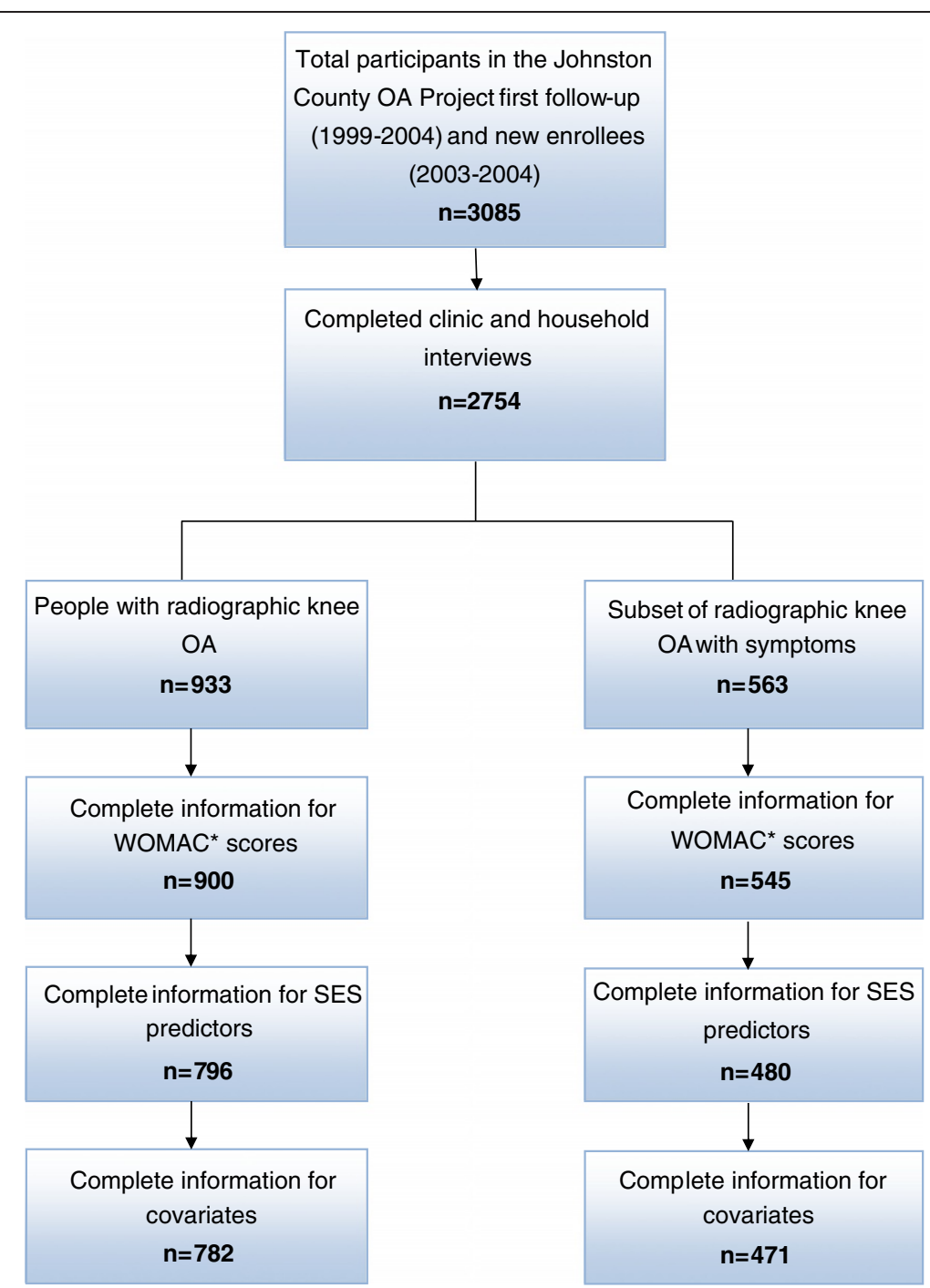

Figure 1 Participant flow chart. *WOMAC = Western Ontario and McMasters Universities Index of Osteoarthritis.

questionnaire were recorded during the clinical interview. The WOMAC questionnaire includes 24 items grouped into three subscales that assess physical function (17 items), pain (5 items), and stiffness (2 items). Participants are asked to rate the degree of discomfort or difficulty in performing a series of tasks, using a 2-day recall period. Responses are measured on a 5 -point Likert-type scale, with higher scores indicating greater pain $(0=$ none, $1=$ mild, $2=$ moderate, $3=$ severe, 4 =extreme) [29]. In this study, the non-weighted WOMAC Total score (range 0-96) was used along with the Function, Pain and Stiffness subscales.

\section{Individual SES measures}

Educational attainment and occupation were measured to represent individual SES status. Measures of educational attainment have been demonstrated to be a good marker of individual SES among persons with OA [15,31-33]. Participants were asked about their highest school year completed and responses were dichotomized between having less than 12 years of school and having 12 or more years of schooling [referent]. U.S. Census employment classifications were used to categorize participants into one of seven occupational groups based on the job they held for the longest period of time. These groups included: (1) farming, forestry or fishing; (2) management or professional; (3) fabrication or manual labor; (4) precise production, crafting, and repair; (5) service; (6) technology, sales or administration; and (7) military [34]. Job classifications were then dichotomized between non-managerial (groups $1,3,4,5$ and 7) and managerial occupations (groups 2 and 6) [referent] according to Census group descriptions. These classifications are used to distinguish occupations that have higher physical demands from occupations that 
focus on office work, have lower physical demands, and tend to include individuals who have higher SES.

\section{Community SES measure}

We measured community SES based on the community poverty rate, defined as the percent of households that fall below the Census Bureau measure of poverty line [35]. Our measure of community poverty was derived using geocoding technology; the physical address of each study participant at the time of evaluation was linked to U.S. Census-extracted household income data at the block group level and assigned a block group identification code. The census block group averages about 1000 residents and represents the participants' most immediate community or neighborhood. A participant's community poverty classification was thereby determined by the block group in which he or she reside, and not by his or her individual circumstances. Participants were categorized based on tertiles of the entire sample resulting in cut-points of $12 \%$ and $25 \%$. This community poverty variable was defined as low (less than $12 \%$ of population live below the poverty line [referent]), medium (12-25\% live below the poverty line), or high (greater than 25\% live below the poverty line). Block group poverty rate has been shown to be a good indicator for community-level SES [36,37].

\section{Other participant characteristics}

Various socio-demographic and clinical characteristics previously associated with knee rOA were collected: age (continuous), Body Mass Index (BMI; weight in $\mathrm{kg} /$ height in $\mathrm{m}^{2}$ ) as an obesity indicator (continuous), gender (male [referent] or female), and self-reported race (Caucasian [referent] or African American). An occupational physical activity score (PAS) was calculated based on the participant's daily report of various occupational activities (standing, walking, squatting and lifting) and the frequency with which he or she performed each activity $(0=$ never, $1=$ seldom, $2=$ sometimes, $3=$ often, and $4=$ always), with final scores ranging from 0-16 [21]. Participant hip pain was collected in the same manner as that for knee pain and was assessed with an affirmative response ("Yes") to the question "On most days, do you have pain, aching or stiffness in your [left/right] hip?" Information was also gathered on the participant's other non-musculoskeletal health issues to ascertain a total co-morbidity count assessed according to the National Health Interview Survey (NHIS), with some modifications. A comorbidity index of 11 diseases (heart disease, high blood pressure, lung disease, cardiovascular disease, ulcer, liver disease, cancer, anxiety/depression, anemia, diabetes, and kidney disease) was created and defined as the sum of positive responses for individual diseases (range 0-11) [24].

\section{Statistical analyses}

Analyses were carried out based on a complete-case dataset where all subjects had complete information for covariates (Figure 1). Due to a modest amount of missing data for participant occupation (8\%) we carried out multiple imputation of missing observations to assess whether the missing data biased our results. We performed multiple imputation of missing occupation using the Markov Chain Monte Carlo method with SAS PROC MI. Results from 10 iterations indicated that there are no meaningful differences in findings from the imputed data compared to a complete-case analysis. Additionally, frequencies of knee disability measures and SES measures were similar for those with complete covariate data and those with at least one missing covariate. Because of these results, and since no individual variables had more than $10 \%$ missing values, the results reported are from the complete-case dataset. All statistical analyses were completed in SAS version 9.2 (SAS Institute Inc., Cary, NC).

Within the knee rOA group and the symptomatic knee rOA subgroup, associations between SES variables with each of the WOMAC outcome scores were calculated using ordinary linear regression (OLR). The WOMAC Total distribution was skewed to the right, with relatively high numbers of low values and residuals that did not conform to the assumption of normality. However, tests with proportional odds models, using disability variables assigned to five ordered classes, resulted in findings of significance that are virtually the same as for ordinary regression, as has previously been reported for WOMAC [38]. Therefore, linear regression was retained for ease in interpreting results. Preliminary regressions involved each of the three individual SES variables included in models alone, adjusted for age, gender, race, BMI, hip pain, comorbidity count, and occupational physical activity score. Further multivariable regressions included simultaneous adjustment for all three SES variables and covariates in order to evaluate independent associations between SES variables and WOMAC outcomes.

\section{Results}

\section{Participants}

Characteristics and mean WOMAC scores for individuals with knee rOA and the subgroup with symptomatic knee rOA are presented in Table 1 . The sample was largely female $(>60 \%)$, with a mean age of 67.4 years in the knee rOA group and 66.2 years in the subset with symptomatic rOA. Participants who self-identified as African American comprised $36.6 \%$ of the full sample and $40.2 \%$ of the symptomatic rOA subgroup. Approximately $36 \%$ of the full sample and $37 \%$ of the subgroup with symptomatic rOA reported completing less than 12 years of education. The overall sample had a BMI of 32.7, with 58\% having a BMI greater than or equal to 30 (a commonly defined marker of 
Table 1 Demographic, SES and WOMAC score characteristics of study participants with rOA and symptomatic ${ }^{5}$ knee rOA

\begin{tabular}{lll}
\hline Variable & Knee rOA & $\begin{array}{l}\text { Subset with } \\
\text { symptomatic } \\
\text { knee rOA } \\
(\mathrm{N}=471)\end{array}$ \\
\hline
\end{tabular}

Demographic and

clinical characteristics

\begin{tabular}{|c|c|c|}
\hline Age, mean (SD) & $67.4(10.8)$ & $66.2(11.0)$ \\
\hline Female, $\%$ & 63.6 & 65.8 \\
\hline $\begin{array}{l}\text { African American } \\
\text { race, } \%\end{array}$ & 36.6 & 40.2 \\
\hline $\mathrm{BMI}^{\ddagger}$, mean (SD) & $32.7(7.58)$ & $33.9(7.87)$ \\
\hline Hip pain,\% & 42.6 & 54.6 \\
\hline $\operatorname{PAS}^{*}(0-16)$, mean (SD) & $9.40(3.58)$ & $9.84(3.54)$ \\
\hline $\begin{array}{l}\text { Co-morbidity count } \\
(0-11) \text {, mean (SD) }\end{array}$ & $1.58(1.38)$ & $1.73(1.44)$ \\
\hline \multicolumn{3}{|l|}{ SES characteristics } \\
\hline Less than 12 yrs education,\% & 35.5 & 36.9 \\
\hline Non-managerial occupation,\% & 39.4 & 35.9 \\
\hline Poverty, mean (SD) & $19.1(11.5)$ & $19.4(11.6)$ \\
\hline Low $(<12 \%), \%$ & 27.0 & 25.9 \\
\hline Medium (12-25\%),\% & 52.8 & 52.4 \\
\hline High (>25\%),\% & 20.2 & 21.7 \\
\hline \multicolumn{3}{|l|}{ WOMAC" Outcomes } \\
\hline $\begin{array}{l}\text { WOMAC Function, } \\
\text { mean (SD) }\end{array}$ & $19.2(16.9)$ & $23.6(16.3)$ \\
\hline $\begin{array}{l}\text { WOMAC }{ }^{\mathbb{1}} \text { Pain, } \\
\text { mean (SD) }\end{array}$ & $5.7(5.1)$ & $7.3(4.9)$ \\
\hline $\begin{array}{l}\text { WOMAC Stiffness, } \\
\text { mean (SD) }\end{array}$ & $2.7(2.2)$ & $3.4(2.1)$ \\
\hline $\begin{array}{l}\text { WOMAC Total, } \\
\text { mean (SD) }\end{array}$ & $27.6(23.2)$ & $34.3(22.1)$ \\
\hline
\end{tabular}

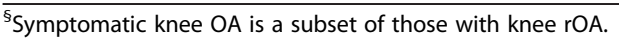

${ }^{\ddagger} \mathrm{BMI}=$ Body Mass Index.

FPAS $=$ Physical activity score related to occupation.

"WOMAC = Western Ontario and McMaster Universities Index of

Osteoarthritis questionnaire.

obesity) and $65 \%$ of the participants in the symptomatic knee rOA subgroup being considered obese. Mean disability scores were generally higher among those within the symptomatic knee rOA subgroup (WOMAC Total $=34.3$ ) as compared to the full knee rOA sample (WOMAC Total $=27.6$, indicating worse overall disability.

\section{Radiographic knee OA analyses}

Parameter estimates for covariate adjusted associations of physical function (WOMAC Function), pain (WOMAC Pain), and stiffness (WOMAC Stiffness), and combined physical function, pain and stiffness (WOMAC Total) scores with SES variables (education, occupation type, community poverty) for all participants with knee rOA, are presented in Table 2. Compared with completing 12 or more years of education, completing less than 12 years of education was positively associated with WOMAC Function scores $(\beta=3.57,95 \% \mathrm{CI}=1.25-5.90)$ and WOMAC Total $(\beta=4.56,95 \% \mathrm{CI}=1.41-7.70)$ scores. Further, having a non-managerial occupation was observed to have positive associations with three WOMAC scores when compared to having a managerial occupation, including WOMAC Function $(\beta=2.91,95 \% C I=0.68-5.14)$, WOMAC Pain $(\beta=0.93,95 \% \mathrm{CI}=0.26-1.59$, and WOMAC Total $(\beta=$ $4.05,95 \% \mathrm{CI}=1.04-7.05)$. Compared with communities with low poverty rates $(<12 \%)$, living in communities with high poverty rates $(>25 \%)$ tended to be positively associated with WOMAC Function and Total scores, of borderline statistical significance (both $p=0.05$ ).

Results from multivariable linear regression analyses to assess independent associations with WOMAC outcomes when all three SES variables were included simultaneously are also presented in Table 2. With simultaneous adjustment for all SES measures, the positive associations between low educational attainment and WOMAC Function and WOMAC Total scores remained statistically significant $(\beta=2.83,95 \% \mathrm{CI}=0.38-5.28 ; \beta=3.48,95 \% \mathrm{CI}=0.18-6.78$, respectively). Further, when compared to having a managerial occupation, having a non-managerial occupation remained significantly associated with higher WOMAC Pain scores $(\beta=0.78,95 \% \mathrm{CI}=0.08-1.48)$, but was no longer significantly associated with WOMAC Function scores or WOMAC Total scores. The associations with WOMAC scores in individual models for having a non-managerial occupation and a high community poverty rate were further attenuated with the inclusion of all SES measures, so the marginal associations seen were no longer significant.

\section{Symptomatic knee OA analyses}

Statistical analyses identical to those for knee rOA were conducted among the subset of individuals with symptomatic knee rOA (Table 3). When compared to living in a community with $<12 \%$ poverty, a statistically significant positive finding was observed between participants living in a community with $>25 \%$ poverty and WOMAC Pain scores $(\beta=1.36, \quad 95 \% \quad C I=0.07-2.65)$. The associations for WOMAC Function scores and WOMAC Total scores approached statistical significance $(\mathrm{p}=0.08 ; 0.06$, respectively). The positive associations of mid-level poverty (12-25\%) also approached statistical significance for WOMAC Function scores and WOMAC Total scores $(\mathrm{p}=0.10 ; 0.09$, respectively), as did the association between having a non-managerial occupation and WOMAC Pain scores when compared to having a managerial occupation $(\mathrm{p}=0.07)$.

Results from multivariable linear regressions of function, pain and stiffness simultaneously adjusted for all SES 
Table 2 Associations ${ }^{\ddagger}$ between SES variables and WOMAC ${ }^{\text {n }}$ outcomes among participants with knee rOA $(n=782)$.

\begin{tabular}{|c|c|c|c|c|}
\hline Effect & $\begin{array}{l}\text { WOMAC Function } \\
\beta^{\ddagger}(95 \% \mathrm{Cl})\end{array}$ & $\begin{array}{l}\text { WOMAC" Pain } \\
\beta^{ \pm}(95 \% \text { Cl })\end{array}$ & $\begin{array}{l}\text { WOMAC Stiffness } \\
\beta^{ \pm}(95 \% \mathrm{Cl})\end{array}$ & $\begin{array}{l}\text { WOMAC Total } \\
\beta^{\ddagger}(95 \% \text { Cl) } \\
\end{array}$ \\
\hline \multicolumn{5}{|l|}{ Individual SES models } \\
\hline$<12$ yrs education ${ }^{*}$ & $3.57(1.25,5.90)^{* *}$ & $0.67(-0.02,1.37)$ & $0.31(0.00,0.62)$ & $4.56(1.41,7.70)^{* *}$ \\
\hline Non-managerial occupation ${ }^{\dagger}$ & $2.91(0.68,5.14)^{*}$ & $0.93(0.26,1.59)^{* *}$ & $0.21(-0.09,0.51)$ & $4.05(1.04,7.05)^{* *}$ \\
\hline Poverty rate $12-25 \%^{\S}$ & $1.76(-0.70,4.23)$ & $0.32(-0.42,1.05)$ & $0.13(-0.20,0.46)$ & $2.21(-1.10,5.54)$ \\
\hline Poverty rate $>25 \%^{\S}$ & $3.18(-0.03,6.39)$ & $0.87(-0.09,1.83)$ & $0.22(-0.21,0.65)$ & $4.27(-0.06,8.60)$ \\
\hline \multicolumn{5}{|c|}{ Mutually ${ }^{\epsilon}$ adjusted SES models } \\
\hline$<12$ yrs education ${ }^{*}$ & $2.83(0.38,5.28)^{*}$ & $0.39(-0.34,1.12)$ & $0.26(-0.07,0.59)$ & $3.48(0.18,6.78)^{*}$ \\
\hline Non-managerial occupation ${ }^{\dagger}$ & $1.96(-0.39,4.30)$ & $0.78(0.08,1.48)^{*}$ & $0.12(-0.19,0.44)$ & $2.86(-0.30,6.02)$ \\
\hline Poverty rate $12-25 \%^{\S}$ & $1.68(-0.77,4.13)$ & $0.30(-0.44,1.03)$ & $0.12(-0.21,0.45)$ & $2.11(-1.20,5.42)$ \\
\hline Poverty rate $>25 \%^{\S}$ & $2.81(-0.38,6.01)$ & $0.77(-0.19,1.73)$ & $0.19(-0.24,0.63)$ & $3.78(-0.54,8.09)$ \\
\hline
\end{tabular}

${ }^{\ddagger}$ Adjusted for age, gender, race, body mass index, hip pain, number of comorbidities and occupational and physical activity score (PAS).

"WOMAC = Western Ontario and McMaster Universities Index of Osteoarthritis questionnaire.

${ }^{\sharp}$ Referent $=12$ years or more education.

${ }^{\dagger}$ Referent $=$ managerial occupation .

${ }^{5}$ Referent $=$ poverty rate $<12 \%$.

${ }^{*} \mathrm{p}<0.05 ;{ }^{* *} \mathrm{p}<0.01$.

${ }^{€}$ All SES measures included in the same model.

measures are also presented in Table 3. The only statistically significant independent SES predictor of WOMAC scores was seen for community poverty rate. When compared to living in a community with a low poverty rate, living in a community with high poverty rate was positively associated with WOMAC Pain scores $(\beta=1.35$, 95\% CI $=0.06-2.64)$. The elevated associations of high community poverty with WOMAC Function and WOMAC Total remained, although they were no longer statistically significant.

\section{Discussion}

This is the first study to examine community SES and individual SES measures simultaneously as predictors of rOA and corresponding symptoms in a communitybased study of African Americans and Caucasians. Our study results indicate that individual SES measures (education and occupation) influence pain and physical function in a cohort of rural, community-dwelling adults with knee rOA. Further, community SES (block group poverty rate) is associated with pain among a subset of

Table 3 Associations ${ }^{\ddagger}$ between SES variables and WOMAC ${ }^{\Uparrow}$ outcomes among participants with symptomatic knee rOA ( $\mathrm{n}=\mathbf{4 7 1 )}$

\begin{tabular}{|c|c|c|c|c|}
\hline Effect & $\begin{array}{l}\text { WOMAC Function } \\
\beta^{\neq}(95 \% \mathrm{Cl})\end{array}$ & $\begin{array}{l}\text { WOMAC Pain } \\
\beta^{\neq}(95 \% \mathrm{Cl})\end{array}$ & $\begin{array}{l}\text { WOMAC Stiffness } \\
\beta^{\neq}(95 \% \mathrm{Cl})\end{array}$ & $\begin{array}{l}\text { WOMAC Total } \\
\beta^{\neq}(95 \% \mathrm{Cl})\end{array}$ \\
\hline \multicolumn{5}{|l|}{ Individual SES models } \\
\hline$<12$ yrs education ${ }^{¥}$ & $2.50(-0.51,5.51)$ & $0.22(-0.69,1.13)$ & $0.17(-0.23,0.56)$ & $2.89(-1.20,6.93)$ \\
\hline Non-managerial occupation ${ }^{\dagger}$ & $2.17(-0.81,5.15)$ & $0.84(-0.06,1.74)$ & $0.09(-0.30,0.49)$ & $3.10(-0.90,7.11)$ \\
\hline Poverty rate $12-25 \%^{\S}$ & $2.77(-0.49,6.04)$ & $0.71(-0.28,1.69)$ & $0.29(-0.14,0.71)$ & $3.77(-0.62,8.15)$ \\
\hline Poverty rate $>25 \%{ }^{\S}$ & $3.80(-0.47,8.08)$ & $1.36(0.07,2.65)^{*}$ & $0.31(-0.25,0.87)$ & $5.47(-0.28,11.2)$ \\
\hline \multicolumn{5}{|c|}{ Mutually ${ }^{\epsilon}$ adjusted SES models } \\
\hline$<12$ yrs education ${ }^{¥}$ & $1.88(-1.30,5.03)$ & $-0.08(-1.00,0.87)$ & $0.14,(-0.28,0.55)$ & $1.94(-2.30,6.17)$ \\
\hline Non-managerial occupation ${ }^{\dagger}$ & $1.60(-1.50,4.71)$ & $0.86(-0.08,1.79)$ & $0.05(-0.36,0.46)$ & $2.51(-1.70,6.69)$ \\
\hline Poverty rate $12-25 \%^{\S}$ & $2.70(-0.56,5.96)$ & $0.71(-0.27,1.69)$ & $0.28(-0.15,0.71)$ & $3.69(-0.69,8.08)$ \\
\hline Poverty rate $>25 \% \S$ & $3.65(-0.63,7.92)$ & $1.35(0.06,2.64)^{*}$ & $0.30(-0.26,0.86)$ & $5.30(-0.45,11.1)$ \\
\hline
\end{tabular}

${ }^{\ddagger}$ Adjusted for age, gender, race, body mass index, hip pain, number of comorbidities and occupational and physical activity score (PAS).

"WOMAC = Western Ontario and McMaster Universities Index of Osteoarthritis questionnaire.

${ }^{¥}$ Referent $=12$ years or more education.

${ }^{\dagger}$ Referent $=$ managerial occupation.

${ }^{\S}$ Referent $=$ poverty rate $<12 \%$.

${ }^{*} \mathrm{p}<0.05 ; * * \mathrm{*}<0.01$.

${ }^{€}$ All SES measures included in the same model. 
individuals with symptomatic knee OA. These data suggest that individuals with knee rOA who are at the highest risk of developing disability and pain are those who have lower SES.

In our analyses, significant associations with pain and physical function remained independently associated with individual and community SES measures for persons with $\mathrm{rOA}$ even when the three SES variables were simultaneously introduced as the main explanatory variables in multivariable analyses. Further, our results remained after adjusting for hip pain, which is also a major contributor to disability. In examining the association with educational attainment more specifically, persons with less than 12 years of education were more likely to have worse WOMAC Function and WOMAC Total scores compared to individuals with higher educational attainment, after adjusting for occupation type and poverty. These results are similar to those found in a recent study by Lopez-Olivio et al. which reported that among individuals who underwent knee replacement, those with less than a high school education had worse WOMAC Pain scores and Function scores when compared with those who had at least a high school education [39]. An additional study using data from the National Health and Nutrition Examination Survey I (NHANES I) found that, among individuals selfreporting knee OA, a low educational level was associated with both more severe radiographic findings as well as more pain [40].

We also observed that persons working in nonmanagerial occupations were more likely to have worse WOMAC Pain scores compared to individuals in managerial positions. Further, persons living in high poverty communities ( $>25 \%$ poverty rate) tended to have worse WOMAC Function and WOMAC Total scores compared to people living in low poverty communities, although not at a level of statistical significance. A recent study reported that adults with chronic knee and/or hip pain who lived in deprived areas were more likely to develop disability [41] while another study reported that patients who lived in areas that were socioeconomically deprived benefitted less from knee replacement surgery than those who did not live in deprived areas [42]. Community poverty may affect those with OA differently, which may lead to greater disability. Communities with high poverty rates often have limited resources including fewer clinics, safe options for public transportation, community centers and safe places to exercise, as well as poorly kept sidewalks and less access to safe streets, all resources that can often contribute to the improvement of function, pain and disability in individuals with OA [43].

Fewer significant associations between SES and pain and disability outcomes were found within the subgroup of individuals with symptomatic knee OA, which may be due to the small subsample size $(n=471)$. In this subsample, multivariable analyses revealed that living in a high poverty community was significantly associated with WOMAC Pain scores, and associations with WOMAC Function scores and WOMAC Total scores approached statistical significance. We are unsure why we found little association between most SES measures and physical function measures. However, our results for this sub-population are in line with those from another study that failed to find an association for education with disability [44].

Overall these results for the associations of SES on disability among those with knee OA are similar to previous findings between SES and disability among those with OA of the hip [23,24,45-47]. This suggests that a broader rOA relationship may exist between SES measures and physical function, pain and stiffness that is not localized to specific joints, further expanding clinical application of the data. This is especially true for individual SES (education and occupation), but may be equally important for community SES as more sensitive and detailed measures of community SES are tested.

To date, the exact mechanisms of how SES leads to disability remain unclear. While physical features such as deformity and muscle weakness are important aspects, other factors may also have a role in disease progression to disability. A number of cross-sectional studies have demonstrated that psychological [48-50], demographic [51], clinical and biomechanical [52] factors are associated with disability among patients with knee OA. These sociodemographic characteristics may influence health behaviors that lead to OA diagnosis (i.e., seeking medical care) or enhance progression of the disease [53]. Although many of these factors were controlled for in our analyses, it is possible that the associations seen may be due to other circumstances associated with SES, such as lifestyle choices (smoking, diet, obesity, physical activity, etc.), demographic characteristics (age and race), or community and psychological factors (perceived helplessness, social support and perceived discrimination) [54,55]. For instance, obesity and low physical activity levels have both been shown to have both direct and indirect effects on physical function and disability [25,54,56,57]. Further, SES may also have an effect on level of medical care itself. Individuals with lower SES levels often do not have access to affordable medical services and interventions or access to quality healthcare, which are important determinants of health outcomes in OA [58].

There are some limitations to our study that warrant mention. Our study was cross-sectional in design so we can only demonstrate an association and not a causal relationship. Also, our measures of knee disability and functional limitations using the WOMAC instrument, 
while widely used, are not perfect. However, the WOMAC instrument can detect differences between better vs. worse outcomes when comparing those with mild or moderate disease vs. those with severe knee OA [59]. Additionally, although the measures are still selfreported, WOMAC is designed specifically to measure pain and function of individuals with lower body OA and is among the most sensitive of all instruments used in the assessment of OA of the knee or hip [29] and has been used extensively in observational studies and clinical trials. Further, studies have shown that the WOMAC pain and function subscales exhibit comparable or greater responsiveness to change than corresponding SF-36 subscales [59-61]. Our measure of community SES (block group poverty) is a somewhat crude measure of community influence. However, area-level poverty has been shown to be a good measure for community-level SES and allows for the assessment of the impact of one's local environment $[36,37]$. Finally, our outcome measure data were self-reported, which may lead to some overestimation of socioeconomic differences in outcomes, compared with more objective clinical measures of impairment.

Strengths include that we carried out our study in a large community-based cohort of individuals with radiographically-confirmed OA instead of self-reported arthritis, with the inclusion of several SES measures and data for comorbid conditions and hip symptoms. In addition, our study is unique in reporting results among a subset of individuals with symptomatic OA to account for pain. Most studies investigating the effectors of SES on disability have only one measure of SES, usually education. However, here we report results that include three SES measures that we evaluated for independent effects. Importantly, we have included a communitylevel measure of SES in addition to typical individuallevel measures.

\section{Conclusions}

The prevalence of knee OA in the U.S. is very high and is projected to increase due to the growing proportion of older adults in the population, and as a repercussion of the obesity epidemic [9]. With a greater population of individuals suffering from disability as a result of knee $\mathrm{OA}$, it is a matter of public health importance to identify and specifically target features associated with knee disability that can be addressed by clinicians. Although most of the SES measures in our study are not easily modifiable, our results underscore the importance of the clinician's involvement in the treatment of OA by not only addressing the symptoms, but also by understanding the patient's context and adapting treatments and interventions based on his or her individual circumstances. Individuals with low levels of education or living in areas with higher poverty levels may need more intensive direction regarding self-management or more help in finding community resources such as weight loss programs that are affordable.

\section{Abbreviations}

BMI: Body mass index; JoCo OA: Johnston County Osteoarthritis; KL: KellgrenLawrence; OA: Osteoarthritis; PAS: Physical activity score; rOA: Radiographic osteoarthritis; SES: Socioeconomic status; WOMAC: Western Ontario and McMaster Universities Index of Osteoarthritis.

\section{Competing interests}

None of the authors have financial or personal relationships to disclose. No funds were provided for writing this manuscript.

\section{Authors' contributions}

RJC participated in analysis and interpretation of data, provided statistical expertise, drafting and critical revision of article. MNL participated in interpretation of data, initial drafting and critical revision of article. JBK participated in drafting and critical revision of article. BS participated in conception and design of study, drafting and critical revision of article, administrative and logistic support. JBR participated in acquisition of data and critical revision of article. JMJ participated in conception and design of study acquisition of data, interpretation of data and critical revision of article. LFC participated in conception and design of study, analysis and interpretation of data, drafting and critical revision of article, and obtaining of funding. She takes responsibility for the integrity of the work as a whole, from inception to finished article. All authors read and approved the final manuscript.

\section{Acknowledgments}

The authors thank the staff of the Johnston County Osteoarthritis Project for their long-standing and dedicated work, as well as the study participants, without whose continuing cooperation none of this research would be possible.

\section{Role of the funding source}

The Johnston County Osteoarthritis Project is supported in part by the Association of Schools of Public Health and the CDC (S043, S1733, and S3486), and by the National Institute of Arthritis and Musculoskeletal and Skin Diseases (P60-AR30701 and P60-AR49465). Additional funding for this project was provided by the National Institute of Arthritis and Musculoskeletal Skin Diseases (NIAMS) (R01-AR-053-989-01), the American College of Rheumatology Research and Education Foundation Award, and a Pre-Doctoral Traineeship to the UNC Institute on Aging by the National Institute on Aging (5T32AG000272). The study sponsors had no involvement in the study design, collection, analysis and interpretation of data; in the writing of the manuscript; and in the decision to submit the manuscript for publication

\section{Author details}

'Thurston Arthritis Research Center, University of North Carolina at Chapel Hill, Chapel Hill, NC, USA. ²Department of Health Behavior, Gillings School of Global Public Health, Thurston Arthritis Research Center, University of North Carolina at Chapel Hill, Chapel Hill, NC, USA. ${ }^{3}$ University of North Carolina School of Medicine, University of North Carolina at Chapel Hill, Chapel Hill, NC, USA. "Thurston Arthritis Research Center and Department of Radiology, University of North Carolina at Chapel Hill, Chapel Hill, NC, USA. ${ }^{5}$ Thurston Arthritis Research Center and Departments of Medicine and Orthopedics, University of North Carolina at Chapel Hill, Chapel Hill, NC, USA. ${ }^{6}$ Thurston Arthritis Research Center and Departments of Medicine and Social Medicine, University of North Carolina at Chapel Hill, Chapel Hill, NC, USA

Received: 8 August 2013 Accepted: 11 October 2013

Published: 17 October 2013

\section{References}

1. Felson DT, Zhang Y: An update on the epidemiology of knee and hip osteoarthritis with a view to prevention. Arthritis \& Rheumatism 1998, 41(8):1343-1355.

2. Hootman JM, Helmick CG: Projections of US prevalence of arthritis and associated activity limitations. Arthritis Rheum 2006, 54(1):226-229. 
3. Lawrence RC, Felson DT, Helmick CG, Arnold LM, Choi H, Deyo RA, Gabriel S, Hirsch R, Hochberg MC, Hunder GG, et al: Estimates of the prevalence of arthritis and other rheumatic conditions in the United States. Part II. Arthritis Rheum 2008, 58(1):26-35.

4. Centers for Disease C, Prevention: Prevalence and most common causes of disability among adults--United States, 2005. MMWR Morb Mortal Wkly Rep 2009, 58(16):421-426.

5. Centers for Disease C, Prevention: Prevalence of doctor-diagnosed arthritis and arthritis-attributable activity limitation --- United States, 2007-2009. MMWR Morb Mortal Wkly Rep 2010, 59(39):1261-1265.

6. Hootman JM, Helmick CG, Brady TJ: A public health approach to addressing arthritis in older adults: the most common cause of disability. Am J Public Health 2012, 102(3):426-433.

7. Hootman JM, Helmick CG, Hannan CJ, Pan L: Prevalence of Obesity Among Adults with Arthritis - United States, 2003-2009. Morbidity and Mortality Weekly Report 2011, 60(16):509-513.

8. Sridhar MS, Jarrett CD, Xerogeanes JW, Labib SA: Obesity and symptomatic osteoarthritis of the knee. J Bone Joint Surg Br 2012, 94(4):433-440.

9. Suri $\mathrm{P}$, Morgenroth DC, Hunter DJ: Epidemiology of osteoarthritis and associated comorbidities. Pm R 2012, 4(5 Suppl):S10-19.

10. Cisternas MG, Murphy LB, Yelin EH, Foreman AJ, Pasta DJ, Helmick CG: Trends in medical care expenditures of US adults with arthritis and other rheumatic conditions 1997 to 2005. J Rheumatol 2009, 36(11):2531-2538.

11. Murphy L, Helmick CG: The impact of osteoarthritis in the United States: a population-health perspective: A population-based review of the fourth most common cause of hospitalization in U.S. adults. Orthop Nurs 2012, 31(2):85-91.

12. Yelin E, Murphy L, Cisternas MG, Foreman AJ, Pasta DJ, Helmick CG: Medical care expenditures and earnings losses among persons with arthritis and other rheumatic conditions in 2003, and comparisons with 1997. Arthritis \& Rheumatism 2007, 56(5):1397-1407.

13. National Center for Health Statistics (U.S.), National Health Examination Survey (U.S.), National Health and Nutrition Examination Survey (U.S.), Hispanic Health and Nutrition Examination Survey (U.S.): Health, United States, 2011: With Special Feature on Socioeconomic Status and Health. Hyattsville, MD: U.S. Dept. of Health and Human Services, Centers for Disease Control and Prevention, National Center for Health Statistics; 2012.

14. Healy WL, Rana AJ, lorio R: Hospital economics of primary total knee arthroplasty at a teaching hospital. Clin Orthop Relat Res 2011, 469(1):87-94.

15. Hannan MT, Anderson JJ, Pincus T, Felson DT: Educational attainment and osteoarthritis: differential associations with radiographic changes and symptom reporting. J Clin Epidemiol 1992, 45(2):139-147.

16. Allen KD, Chen JC, Callahan LF, Golightly YM, Helmick CG, Renner JB, Jordan JM: Associations of occupational tasks with knee and hip osteoarthritis: the Johnston County Osteoarthritis Project. J Rheumatol 2010, 37(4):842-850

17. Andersen S, Thygesen LC, Davidsen M, Helweg-Larsen K: Cumulative years in occupation and the risk of hip or knee osteoarthritis in men and women: a register-based follow-up study. Occup Environ Med 2012, 69(5):325-330.

18. Chen JC, Linnan L, Callahan LF, Yelin EH, Renner JB: Workplace policies and prevalence of knee osteoarthritis: the Johnston County Osteoarthritis Project. Occup Environ Med 2007, 64(12):798-805.

19. Sandmark H, Hogstedt C, Vingard E: Primary osteoarthrosis of the knee in men and women as a result of lifelong physical load from work. Scand J Work Environ Health 2000, 26(1):20-25.

20. Callahan LF, Cleveland RJ, Shreffler J, Schwartz TA, Schoster B, Randolph R, Renner JB, Jordan JM: Associations of educational attainment, occupation and community poverty with knee osteoarthritis in the Johnston County (North Carolina) osteoarthritis project. Arthritis Res Ther 2011, 13(5):R169.

21. Callahan LF, Shreffler J, Siaton BC, Helmick CG, Schoster B, Schwartz TA, Chen JC, Renner JB, Jordan JM: Limited educational attainment and radiographic and symptomatic knee osteoarthritis: a cross-sectional analysis using data from the Johnston County (North Carolina) Osteoarthritis Project. Arthritis Res Ther 2010, 12(2):R46.

22. Cleveland RJ, Schwartz TA, Prizer LP, Randolph R, Schoster B, Renner JB, Jordan JM, Callahan LF: Associations of educational attainment, occupation and community poverty with hip osteoarthritis. Arthritis Care Res (Hoboken) 2013, 65(6):954-961.

23. Juhakoski R, Tenhonen S, Anttonen T, Kauppinen T, Arokoski JP: Factors affecting self-reported pain and physical function in patients with hip osteoarthritis. Arch Phys Med Rehabil 2008, 89(6):1066-1073.
24. Knight JB, Callahan LF, Luong ML, Shreffler J, Schoster B, Renner JB, Jordan JM: The association of disability and pain with individual and community socioeconomic status in people with hip osteoarthritis. Open Rheumatol J 2011, 5:51-58

25. Peters TJ, Sanders C, Dieppe P, Donovan J: Factors associated with change in pain and disability over time: a community-based prospective observational study of hip and knee osteoarthritis. Br J Gen Pract 2005, 55(512):205-211.

26. Jordan JM, Helmick CG, Renner JB, Luta G, Dragomir AD, Woodard J, Fang F, Schwartz TA, Abbate LM, Callahan LF, et al: Prevalence of knee symptoms and radiographic and symptomatic knee osteoarthritis in African Americans and Caucasians: the Johnston County Osteoarthritis Project. J Rheumatol 2007, 34(1):172-180.

27. Kellgren JH, Lawrence JS: Radiological assessment of osteo-arthrosis. Ann Rheum Dis 1957, 16(4):494-502

28. Jordan JM, Linder GF, Renner JB, Fryer JG: The impact of arthritis in rural populations. Arthritis Care Res 1995, 8(4):242-250.

29. Bellamy N, Buchanan WW, Goldsmith CH, Campbell J, Stitt LW: Validation study of WOMAC: a health status instrument for measuring clinically important patient relevant outcomes to antirheumatic drug therapy in patients with osteoarthritis of the hip or knee. J Rheumatol 1988, 15(12):1833-1840.

30. McConnell S, Kolopack P, Davis AM: The Western Ontario and McMaster Universities Osteoarthritis Index (WOMAC): a review of its utility and measurement properties. Arthritis Rheum 2001, 45(5):453-461.

31. Callahan LF, Smith WJ, Pincus T: Self-report questionnaires in five rheumatic diseases: comparisons of health status constructs and associations with formal education level. Arthritis Care Res 1989, 2(4):122-131.

32. Leigh JP, Fries JF: Education level and rheumatoid arthritis: evidence from five data centers. J Rheumatol 1991, 18(1):24-34

33. Pincus T, Callahan LF, Burkhauser RV: Most chronic diseases are reported more frequently by individuals with fewer than 12 years of formal education in the age 18-64 United States population. J Chronic Dis 1987 40(9):865-874.

34. States U: Bureau of the Census.: 1990 census of population and housing. Alphabetical index of industries and occupations. U.S. Dept. of Commerce, Economics and Statistics Administration For sale by the U.S. G.P.O., Supt. of Docs.: Washington, DC; 1992.

35. Dalaker J, U.S. Census Bureau: Poverty in the United States, 2000. In Current population reports Series P-60, Consumer income no 214. Washington, D.C: U.S. Dept. of Commerce, Census Bureau. For sale by the U.S. G.P.O., Supt. of Docs.: 2001: iv, 28 p. col. ill., map $28 \mathrm{~cm}$.

36. Diez Roux AV, Merkin SS, Arnett D, Chambless L, Massing M, Nieto FJ, Sorlie P, Szklo M, Tyroler HA, Watson RL: Neighborhood of residence and incidence of coronary heart disease. N Engl J Med 2001, 345(2):99-106.

37. Krieger N, Zierler S, Hogan JW, Waterman P, Chen J, Lemieux K, Gjelsvik A: Geocoding and measurement of neighborhood socioeconomic position: a US perspective. In Neighborhoods and Health. Edited by Kawachi I Berkman LF. New York: Oxford University Press; 2003:147-178.

38. Allen KD, Helmick CG, Schwartz TA, DeVellis RF, Renner JB, Jordan JM: Racial differences in self-reported pain and function among individuals with radiographic hip and knee osteoarthritis: the Johnston County Osteoarthritis Project. Osteoarthritis Cartilage 2009, 17(9):1132-1136.

39. Lopez-Olivo MA, Landon GC, Siff SJ, Edelstein D, Pak C, Kallen MA, Stanley M, Zhang H, Robinson KC, Suarez-Almazor ME: Psychosocial determinants of outcomes in knee replacement. Ann Rheum Dis 2011, 70(10):1775-1781.

40. Leigh JP, Fries JF: Correlations between education and arthritis in the 1971-1975 NHANES I. Soc Sci Med 1994, 38(4):575-583.

41. Ayis $S$, Dieppe $P$ : The natural history of disability and its determinants in adults with lower limb musculoskeletal pain. J Rheumatol 2009, 36(3):583-591.

42. Neuburger J, Hutchings A, Black N, van der Meulen JH: Socioeconomic differences in patient-reported outcomes after a hip or knee replacement in the English National Health Service. J Public Health (Oxf) 2013, 35(1):115-124.

43. Martin KR, Shreffler J, Schoster B, Callahan LF: Associations of perceived neighborhood environment on health status outcomes in persons with arthritis. Arthritis Care Res (Hoboken) 2010, 62(11):1602-1611.

44. Creamer P, Lethbridge-Cejku M, Hochberg MC: Factors associated with functional impairment in symptomatic knee osteoarthritis. Rheumatology (Oxford) 2000, 39(5):490-496. 
45. Dieppe P, Judge A, Williams S, Ikwueke I, Guenther KP, Floeren M, Huber J, Ingvarsson T, Learmonth I, Lohmander LS, et al: Variations in the preoperative status of patients coming to primary hip replacement for osteoarthritis in European orthopaedic centres. BMC Musculoskelet Disord 2009, 10:19.

46. Schafer T, Krummenauer F, Mettelsiefen J, Kirschner S, Gunther KP: Social, educational, and occupational predictors of total hip replacement outcome. Osteoarthritis Cartilage 2010, 18(8):1036-1042.

47. Juhakoski R, Malmivaara A, Lakka TA, Tenhonen S, Hannila ML, Arokoski JP: Determinants of pain and functioning in hip osteoarthritis - a two-year prospective study. Clin Rehabil 2013, 27(3):281-287.

48. Dekker J, Boot B, van der Woude LH, Bijlsma JW: Pain and disability in osteoarthritis: a review of biobehavioral mechanisms. J Behav Med 1992, 15(2):189-214

49. Salaffi F, Cavalieri F, Nolli M, Ferraccioli G: Analysis of disability in knee osteoarthritis. Relationship with age and psychological variables but not with radiographic score. J Rheumatol 1991, 18(10):1581-1586.

50. Summers MN, Haley WE, Reveille JD, Alarcon GS: Radiographic assessment and psychologic variables as predictors of pain and functional impairment in osteoarthritis of the knee or hip. Arthritis Rheum 1988, 31(2):204-209.

51. Sainio $P$, Martelin T, Koskinen $S$, Heliovaara M: Educational differences in mobility: the contribution of physical workload, obesity, smoking and chronic conditions. J Epidemiol Community Health 2007, 61(5):401-408.

52. van Baar ME, Dekker J, Lemmens JA, Oostendorp RA, Bijlsma JW: Pain and disability in patients with osteoarthritis of hip or knee: the relationship with articular, kinesiological, and psychological characteristics. J Rheumatol 1998, 25(1):125-133.

53. Adler NE, Newman K: Socioeconomic disparities in health: pathways and policies. Health Aff (Millwood) 2002, 21(2):60-76.

54. Verbrugge LM, Gates DM, Ike RW: Risk factors for disability among U.S. adults with arthritis. J Clin Epidemiol 1991, 44(2):167-182.

55. Luong ML, Cleveland RJ, Nyrop KA, Callahan LF: Social determinants and osteoarthritis outcomes. Aging health 2012, 8(4):413-437.

56. Ling SM, Xue QL, Simonsick EM, Tian J, Bandeen-Roche K, Fried LP, Bathon JM: Transitions to mobility difficulty associated with lower extremity osteoarthritis in high functioning older women: longitudinal data from the Women's Health and Aging Study II. Arthritis Rheum 2006, 55(2):256-263.

57. van Dijk GM, Dekker J, Veenhof C, van den Ende CH: Course of functional status and pain in osteoarthritis of the hip or knee: a systematic review of the literature. Arthritis Rheum 2006, 55(5):779-785.

58. Marmot M, Friel S, Bell R, Houweling TA, Taylor S: Closing the gap in a generation: health equity through action on the social determinants of health. Lancet 2008, 372(9650):1661-1669.

59. Brazier JE, Harper R, Munro J, Walters SJ, Snaith ML: Generic and conditionspecific outcome measures for people with osteoarthritis of the knee. Rheumatology (Oxford) 1999, 38(9):870-877.

60. Angst F, Aeschlimann A, Steiner W, Stucki G: Responsiveness of the WOMAC osteoarthritis index as compared with the SF-36 in patients with osteoarthritis of the legs undergoing a comprehensive rehabilitation intervention. Ann Rheum Dis 2001, 60(9):834-840.

61. Davies GM, Watson DJ, Bellamy N: Comparison of the responsiveness and relative effect size of the western Ontario and McMaster Universities Osteoarthritis Index and the short-form Medical Outcomes Study Survey in a randomized, clinical trial of osteoarthritis patients. Arthritis Care Res 1999, 12(3):172-179.

doi:10.1186/1471-2474-14-297

Cite this article as: Cleveland et al: Independent associations of socioeconomic factors with disability and pain in adults with knee osteoarthritis. BMC Musculoskeletal Disorders 2013 14:297.

\section{Submit your next manuscript to BioMed Central and take full advantage of:}

- Convenient online submission

- Thorough peer review

- No space constraints or color figure charges

- Immediate publication on acceptance

- Inclusion in PubMed, CAS, Scopus and Google Scholar

- Research which is freely available for redistribution

Submit your manuscript at www.biomedcentral.com/submit
C Biomed Central 